\title{
Discourse Markers in EFL Student Presentations
}

\author{
Titik Rahayu $^{1}$, Muhyiddin Aziz ${ }^{2}$, Ita Permatasari ${ }^{3}$, Alief Sutantohadi ${ }^{4}$, Yulius Harry Widodo ${ }^{5}$ \\ State Polytechnic of Madiun, Serayu St. $84^{\text {th }}$ Madiun City $1,2,3,4,5$ \\ $\left\{\right.$ titikrahayu@pnm.ac.id $\left.{ }^{1}\right\}$
}

\begin{abstract}
Discourse Markers (DMs) have a significant role both in oral and written communication. DMs particularly in spoken language support the audience in interpreting meanings. In a discourse, all segments indicate distinct connections. The relations of the segments vary from changing topics, contrasting, elaborating, to inferring. By the use of DMs, the hearers can guess the signal of connections among segments. Despite various choices of DMs that can be used, EFL learners had a tendency to use only common DMs. The use of DMs in an EFL context is interesting to discuss to reveal the students' ability in building cohesion and coherence in their speaking performances. Therefore, this current research is aimed to find out the most frequently used variants of DMs and to investigate the appropriate and inappropriate uses of DMs in student presentations. The discourse analysis was applied to analyze 86 presentation videos produced by students enrolling in Intermediate Speaking Course. The results revealed that the most frequently used DMs are and, also, but, so, and however. The misuses of DMs were mostly pertinent to the overuse and surface logicality.
\end{abstract}

Keywords: Discourse Markers, Student Presentations, Spoken Discourse

\section{Introduction}

The uses of Discourse Markers (henceforth DMs) in written and spoken language have taken interests for researchers. Some studies [1]-[3] investigated the use of DMs in written contexts. Some studies [4]-[8] focused on investigating the use of DMs in spoken contexts. The studies applied corpus-based analysis to investigate DMs and discussed them pragmatically. The results showed a variety of data on the variants of DMs used in different types of texts, their functions behind their occurrence within contexts, the quality of students' writing or speaking by using DMs, and also the appropriateness or inappropriateness of using DMs.

Some researchers agree to say that the use of DMs in various types of texts can provide cohesion to ease the hearers or readers for comprehending the meaning of the texts. Various techniques can be used to build a coherent text but using DMs gives more effectiveness to link the meaning of between or among segments. In other words, DMs contribute to the cohesion building. The occurrence of DMs to some extent increases the clarity of relations among ideas in a written or spoken language.

In nature, spoken language is different from written language since it is spontaneous [9]. Spoken language needs signs to make the hearers grasp the connectivity of among ideas 
effortlessly. Without connectivity among ideas, speakers will find difficulties to arrange words appropriately and this situation results to the occurrence of incoherent utterances. Both hearers and speakers need clues to link ideas. Hearers can have an easier interpretation, and speakers can convey their talk by knowing the relation of their ideas with the assistance of DMs.

Various DMs are commonly employed by native and non-native English speakers in spoken contexts. In research conducted by Aşik and Cephe [4], the native speakers use and, umm, so, but, just, okay, you know, really, because, and yeah. On the other hand, the nonnative students use uhh, and, so, yes, but, umm, for example, let's, as, because, and or. Similarly, in a study [3], there are five common DMs produced by the learners (um and $u h$, you know, like, well and oh). With regard to the application of DMs by English learners, Rongrong and Lixun [10] conducted research on the use of DMs in the teacher talk. The results showed okay, so, and, right/all right, now, yes, but, just, um, and oh as the top ten DMs. Vickov and Jakupčević [11] analyzed the use of DMs in EFL teacher talk and found three frequently used DMs that are $o k$, so, and and. The mentioned variants of DMs have their own functions based on the context of their occurrence.

Fraser [12] states the main function of DMs in a discourse. DMs provide a sign of the connection of two segments in a discourse. Segments in a discourse have to be connected to build coherence and to avoid ambiguity. Although some findings showed the occurrence of DMs in a discourse will not always build coherence, the use of DMs can lead to the successful communication and it is necessary for English learners to be aware of using DMs [13]. DMs can be used to indicate the changing topic as a warning for the hearers. Besides, it provides links ideas in a discourse whether the preceding segments are contrastive or elaborative to the following segment. DMs also indicate the relation that the following segment contains an inference.

Fraser [14] classifies DMs into four categories namely topic change markers, contrastive markers, elaborative markers, and inferential markers. Topic change markers have a role to sign the movement between one to another topic. Thus, if there is an occurrence of these markers, the speaker gives a sign that he/she talks a different topic. The topic can be still relevant or completely different from the preceding segment. Contrastive markers give a sign that the next segment is contrast with the preceding segment. It facilitates the hearers in interpreting contrastive ideas. Elaborative markers provide signals to the hearers that the next segment will give more explanation on the previous segment. Inferential markers provide signals that the following segment makes an inference according to the previous one.

In a speaking class, many activities can explore the students' ability to build coherence and cohesion by using four types of DMs. As suggested by Parrot [13], presentations are recommended to make students practice speaking. Students do monologues by dividing the parts of presentations into three: the opening, the body, and the close. In a presentation, students need their ability in applying DMs for connecting segments. They can use topic change markers, contrastive markers, elaborative markers, and inferential markers.

Students find some difficulties in using DMs because the concept of DMs is beyond the sentence level. Comprehension, style, word order, and form are typically found by learners while using DMs [15]. Learners may make a mistake while using a DM on the contrary. The DM is rarely used in daily conversation that results the lack of understanding the meaning and function of the DM especially for EFL students. Both native and non-native speakers tend to use a monotonous style in using DMs for instance using so for expressing a result and but for expressing a contrast. The difficulty on word order is the misunderstanding of locating DMs in sentences. Some DMs can be used in the beginning, middle, or the end of sentence for 
example indeed and after all. However, most of DMs are commonly used only in the beginning of sentences for example similarly and in other words. For DMs that are rarely used, students have a tendency to make a mistake such as as effect instead of as a result. In addition, Kao and Chen [16] categorize the misuses of DMs into six misuse patterns. The definition of each misuse is presented as follows.

Table 1. Misuse Patterns of DMs

\begin{tabular}{cll}
\hline No & Misuse Pattern & \multicolumn{1}{c}{ Definition } \\
\hline 1 & $\begin{array}{l}\text { Non-equivalent } \\
\text { exchange }\end{array}$ & $\begin{array}{l}\text { The DMs used for notifying the } \\
\text { similar textual relation in an } \\
\text { interchangeable method when } \\
\text { actually they are not } \\
\text { The high density of the occurrence } \\
\text { of DMs } \\
\text { The use of DMs to impose } \\
\text { logicality or bridge the gap among } \\
\text { propositions when actually their } \\
\text { existence does not } \\
\text { The failure of using a particular } \\
\text { DM to sign a certain textual relation } \\
\text { The lack of explanation that makes } \\
\text { a DM less functional } \\
\text { The pointless uses of DMs }\end{array}$ \\
\hline
\end{tabular}

In accordance with the previous studies, this current research is aimed to investigate the most frequently used DMs in EFL student presentations and the appropriate and inappropriate uses of DMs.

\section{Method}

This research was conducted by analysing the spoken language produced by EFL students in the form of monologues (presentations). A discourse analysis was applied to know the uses of DMs in student spoken performances. The language use in this research was analysed using quantitative and qualitative data to achieve the research objectives. The quantitative data were presented through the checklists of the uses of DMs in student presentations. Then, qualitative data were shown to present the appropriate and inappropriate uses of DMs.

The data in this research were 86 videos of student presentations from Class 2A, 2B, and 2C English Study Program, Business Administration Department, State Polytechnic of Madiun. They enrolled in Intermediate Speaking Course once a week. This course has one credit and three hours. As the background skill, all students had passed Basic Speaking Class in the first semester. They have learned common expressions to be used in conversations in the formal and informal registers. Different from Basic Speaking, Intermediate Speaking has various activities such as performing in front of the class in which they had to do monologues in the form of individual presentations. In the activities, the uses of DMs are necessary to increase the quality of their spoken performances in the terms of coherence, cohesion, and fluency.

The data collection was conducted in the second semester of the academic year of 2019/2020. The period of the semester was started from January till May 2020. One of the researchers taught Intermediate Speaking Class for Class A, B, and C. In Intermediate 
Speaking Course, all classes had the same assignments along the semester in which they were assigned by the lecturer to produce a presentation video with a specific topic "Describing Tourist Destinations". The time allotment for the presentation was approximately 3 minutes for every student. Their video was uploaded in Google Classroom as the learning platform for the course during the pandemic.

The process of the classroom activity includes the following steps: (1) lecturing, (2) planning, and (3) performing. In the lecturing, they received materials shared in Google Classroom in the form of presentation video. The materials were about how to describe a tourist destination properly. The topic was chosen as the students of English program have two concentrations which are tourism and journalism and this topic was closely related to the tourism field. In the video, the students found materials including how to do a good presentation and the useful language uses. As the initial activity, in the planning stage, students had their own decision to choose what title was preferable for them. They were given an opportunity to choose any tourism place that they have ever visited for example Sarangan Lake and Lawu Park. In their presentation, they were not allowed to read texts as they were in a "reading aloud" activity. Pictures of their tourist destination were suggested to be used as visual media to create more impressive videos. Then, they recorded their presentation in a video with the length about 3 minutes. Finally, they uploaded their video to Google Classroom to complete the assignment.

The instruments for collecting the data were a DM rubric and checklists. The DM rubric is used as the guideline for focusing the research. The rubric contains four types of DMs namely topic change markers, elaborative markers, contrastive markers, and inferential markers. All the variants under each type were defined and the researchers state the functions.

Checklists display the data of DMs used in student presentations. The checklists were also completed with codes to ease the analysis process. For instance, A1 was used to indicate the video was from Class A and was analyzed in the first order. B3 indicated that the video was from Class B and was analyzed in the third order. The order was randomly made and it is not related with the level of score of the students in the video. For knowing the functions and the appropriate and inappropriate uses of DMs, the researchers watched the video and analyzed the use of DMs within segments in the context.

The researchers used two steps to find out the most frequently used DMs in EFL student presentations and the appropriate and inappropriate uses of DMs. The first step was counting the frequency distribution of DMs by making checklists. The analysis focused only on the variants listed by Fraser [14] shown in Table 2.

Table 2. Variants of DMs According to DMs Types

\begin{tabular}{|c|c|c|}
\hline No & Type & Variant \\
\hline 1 & $\begin{array}{l}\text { Topic } \\
\text { change } \\
\text { markers }\end{array}$ & $\begin{array}{l}\text { back to my original point, before I forget, by the way, incidentally, just to } \\
\text { update you, on a different note, parenthetically, put another way, returning to } \\
\text { my point, speaking of X, that reminds me. }\end{array}$ \\
\hline 2 & $\begin{array}{l}\text { Contrastive } \\
\text { markers }\end{array}$ & $\begin{array}{l}\text { all the same, anyway, but, contrariwise, conversely, despite (this/that), even so, } \\
\text { however, in any case/rate/event, in spite of (this/that), in comparison (with } \\
\text { this/that), in contrast (to this/that), instead (of doing this/that), nevertheless, } \\
\text { nonetheless, (this/that point) not-withstanding, on the other hand, on the } \\
\text { contrary, rather (than do this/that), regardless (of this/that), still, that said, } \\
\text { though, yet. }\end{array}$ \\
\hline 3 & $\begin{array}{l}\text { Elaborative } \\
\text { markers }\end{array}$ & $\begin{array}{l}\text { above all, also, alternatively, analogously, and, besides, better, by the same } \\
\text { token, correspondingly, equally, for example/instance, further(more), in } \\
\text { addition, in any caselevent, in fact, in other words, in particular, indeed, }\end{array}$ \\
\hline
\end{tabular}




\begin{tabular}{|c|c|c|}
\hline No & Type & Variant \\
\hline 4 & $\begin{array}{l}\text { Inferential } \\
\text { markers }\end{array}$ & $\begin{array}{l}\text { likewise, more accurately, more importantly, more precisely, more specifically, } \\
\text { more to the point, moreover, on that basis, on top of it all, or, otherwise, } \\
\text { similarly, that is, to cap it all off, too, what is more. } \\
\text { accordingly, after all, all thing considered, as a consequence, as a logical } \\
\text { conclusion, as a result, because of this/that, consequently, for this/that reason, } \\
\text { hence, in this/that case, it can be concluded that, it stands to reason that, of } \\
\text { course, on this/that condition, so, then, therefore, thus. }\end{array}$ \\
\hline
\end{tabular}

The researchers ignored the occurrences of two DMs joined together as one meaning for example and then, and also, and so, or and now. Some variants that have functions not only as a DM but also as a conjunction are not counted. For instance, and can be used for joining two or more nouns, verbs, and adjectives in a sentence. The instance constitutes the use of and as a conjunction, not as a DM.

The second step was determining the appropriate and inappropriate uses of DMs. The appropriateness was investigated by matching the function of DMs with the context in which the DMs deployed. The inappropriateness was aimed to show the students' misuse patterns in using DMs in the spoken discourse by following the categories shown in Table 1.

In brief, the data analysis dealt with two main steps: counting the frequency of DMs and presenting samples of the appropriateness or inappropriateness of the use of DMs in EFL student presentations.

\section{Findings and Discussion}

\subsection{Findings}

\section{a) The Most Frequently Used DMs in EFL Student Presentations}

The initial aim of this research is to investigate the most frequently used DMs in student presentations. The findings showed that DMs occurred in four different types. There were 20 variants with a different frequency and percentage. All types categorized by Fraser [14] were used by students in describing a tourist destination. From all variants listed, students had a tendency to use some of them in a high number of occurrences. The complete data are shown in Table 3.

Table 3. The Frequency Distribution of DMs in Students' Speaking Performances

\begin{tabular}{ccccc}
\hline No & Type & Variant & Frequency & \% \\
\hline 1 & Elaborative & and & 158 & 34.65 \\
& Marker & also & 85 & 18.64 \\
& & for example & 15 & 3.29 \\
& & in addition & 6 & 1.32 \\
& & or & 6 & 1.32 \\
& besides & 5 & 1.10 \\
& & furthermore & 4 & .88 \\
& in fact & 3 & .66 \\
& more & 2 & .44 \\
& & specifically & & \\
& & too & 2 & .44 \\
& & more precisely & 1 & .22 \\
\hline
\end{tabular}




\begin{tabular}{|c|c|c|c|c|}
\hline No & Type & Variant & Frequency & $\%$ \\
\hline \multirow[t]{4}{*}{2} & Contrastive & but & 61 & 13.38 \\
\hline & Marker & however & 33 & 7.24 \\
\hline & & still & 3 & .66 \\
\hline & & though & 1 & .22 \\
\hline \multirow[t]{4}{*}{3} & Inferential & so & 52 & 11.40 \\
\hline & Marker & then & 9 & 1.97 \\
\hline & & of course & 5 & 1.10 \\
\hline & & therefore & 2 & .44 \\
\hline \multirow[t]{2}{*}{4} & Topic Change & by the way & 3 & .66 \\
\hline & \multicolumn{2}{|c|}{ Total Number } & 156 & 100 \\
\hline
\end{tabular}

In Table 3, it reveals the total number of DMs which is 456. The type of DMs with the highest percentage is the elaborative markers with $62.94 \%$. Contrastive markers have the second position with $21.49 \%$. Inferential markers are in the third position with $14.91 \%$. The type of DMs with a lowest usage is topic change markers with $0.66 \%$. As the highest type of DMs used by students, elaborative markers have 11 variants with a various number of frequency. The result reveals two variants used above 5\% that are and and also. Contrastive markers have two common variants (but and however) followed by inferential markers with only one common variant which is so.

The topic change marker is the type of DMs rarely used by students with $0.66 \%$. The only variant found was by the way. Although there were many variants that are possible to be used in the presentation for changing a topic, it can be seen that by the way is the most common topic change marker. From the result, it implies that students favour to use elaborative markers to explain a tourist destination. They used them as a sign for elaborating their main ideas by adding more information or presenting examples. The most frequently used DMs in student presentations are and, also, but, so, and however with a percentage above 5\%.

\section{b) The Appropriate and Inappropriate Uses of DMs in EFL Student Presentations}

Variants of DMs can be used correctly by students in their presentation to describe a tourist destination. The appropriate uses consider the relevance of the function and the context of DMs embedded. Besides, the appropriateness also considers the necessity of using DMs or not. For the clear description, five samples of appropriate uses of the five frequently used DMs found in student presentations are presented below.

1) For adults is Rp 150000 for one person, for children 2-12 years old is Rp 75000 for one person. And for under 2 years is free.

2) The beautiful view is also supported by good and complete facilities.

3) We can also try paragliding but it should be accompanied by an expert.

4) The waterfall is on $105 \mathrm{~m}$ level. So, the panorama of the waterfall looks so beautiful.

5) However, there is a problem like a hard rain fall especially in December. So how to deal with this problem?

In Excerpt 1, and is used correctly and also showed its function for connecting the preceding segment and the following segment. Both segments describe the entrance ticket to go to a particular tourist destination. Then, and indicates that the following segment is the end of the explanation for the preceding segment. In Excerpt 2, also is used to indicate the 
elaboration of the similar information of the previous segment. It can be seen that the previous segment describes the beautiful view of a particular place and the view is completed with adequate facilities. In Excerpt 3, but is used to warn the visitors in doing an action mentioned in the previous segment. The existence of but is significant because it contrasts the idea of "try" with "accompanied by an expert." It means that the action is dangerous and should be tried with an expert. In Excerpt 4, so is used for indicating that the following segment is a result of the idea in the previous segment. The waterfall is in the level high ground, therefore the panorama is beautiful. Lastly, in Excerpt 5, however is correctly used to indicate two ideas in two segments. The previous segment describes the astonishing depiction of a place, and the following segment describes or even warns visitors to be well prepared with unexpected conditions that might appear.

From the findings, it was also found that there were inappropriate uses of DMs that falls into six categories of miuses: distraction, overuse, surface logicality, wrong relation, semantic incompletion, and equivalent exchange. Six samples are chosen for displaying the inappropriate use of each category.

6) This is Grojogan Sewu you can visit...and the water is so cold, it is so cold...and it is so..yeah you can refresh with this location or spot.

7) But if you want an exciting adventure you can also enjoy the view, the beautiful scenery of Bau Bau City to the Nirwana Beach by on foot.

8) If you confused about the map..because when I go there I just following my map and I got confused so I decided asked some natives people of there. But it's gonna take very very hard rider and you know.... but it's worth you know ...

9) Because with a large area if we walk it's very tired. However, there would be some problem.

10) They are so many spots you can visit for vacation errr in Sarangan Lake. So I will tell you ee some ...

11) The place is quite far from the city. So, you need an hour to arrive in your destination.

In Excerpt 6, there is a case of distraction. The segments are coherent without the use of and or any DM within the segments. In Excerpt 7, it shows the misuse in overuse. But and also are used in the same sentence. In fact, the variant but is enough for connecting the previous segment and the next segment. In Excerpt 8, the misuse of but deals with surface logicality. The logicality among the segments cannot be clearly shown with the occurrence of the variant. In Excerpt 9, the function of however is not suitable with the context of the previous segment. The previous segment describes a problem, but the next segment also describes the same thing. With the same level of meaning, however should be changed into elaborative marker. Therefore, the misuse is in the wrong relation. In Excerpt 10, so is misused as semantic incompletion. The previous segment should present more information to lead to the next segment. Thus, the use of so is not confusing as it is shown in the sentence. In Excerpt 11, the misuse of so deals with non-equivalent exchange in which the previous segment is not the cause of the second segment. Indeed, the second segment adds more information of the previous segment.

From 14 samples analysed taken from five common variants used in student presentations, the highest number is the misuse related to overuse with five occurrences. In the second position, surface logicality shows three occurrences. For wrong relation and distraction have the same number which is two occurrences. Non-equivalent exchange and semantic 
incompletion have only one occurrence. The samples of misuses represent the common cases found in student presentations.

\subsection{Discussion}

\section{a) The Most Frequently Used DMs in EFL Student Presentations}

All types of DMs are found in student presentations with different number of frequency. Although there are many options of variants that can be used, students tended to choose particular variants that seem commonly used by the learners on the daily basis. There are 20 variants out of $88 \mathrm{DMs}$ listed by Fraser [14] used by students in their presentation. From the 20 variants, students tended to favour only several variants: and, also, but, so, and however. The variants were proven to be frequently used by EFL learners in some previous studies of DMs in spoken contexts.

In a spoken performance like a presentation, students need to back to the previous point, change the subject, and emphasize an important statement. However, only three out of 86 students used a variant of topic change markers, by the way. It implies that the students are not familiar to use this type of DMs in their presentations especially when they talked about a tourist destination in the formal context.

\section{b) The Appropriate and Inappropriate Uses of DMs in EFL Student Presentations}

This research is also aimed to find out the appropriate and inappropriate uses of DMs in the speaking performances of students. The appropriate uses were shown in findings by considering the correctness between the functions of the DMs and the context they are employed. The context was investigated by analysing the previous and the following segments connected by a DM.

From the findings on appropriateness, students were able to express their thoughts into correct and understandable language. They showed their efforts to use DMs into their speaking performance as this case showed their awareness on building coherence and cohesion in spoken language. The awareness is a good signal for the students to explore more DMs and to practice to use various DMs on connecting segments in a spoken discourse. The strategy can help them to avoid the monotonous occurrence of a particular DM such as and.

The findings on inappropriateness show that the students had a tendency to overuse DMs in their presentation. The DMs were used as fillers that give them a moment to think for what they would like to say. For some students, they had a tendency for using a particular DM in every sentence such as and, also, and but. However, the overuse somehow made their speaking natural and they showed another level of fluency compared to those who followed the script. Indeed, the overuse is mostly used by students who are fluent in speaking. The criteria of the fluency are the ability to speak naturally without any sign of memorizing every single word by showing some improvisation while presenting their topic.

The surface logicality also becomes a problem for students. The uses of DMs are failed to develop a reasonable thinking between two segments. The cases were found when the students used and, so, and but. Students use them simply two connect segments without thinking about the coherence and cohesion of two segments. This is caused by the lack of knowledge dealing with variants of DMs.

The results of the study implies that the teaching and learning process should emphasize the use of DMs by showing some samples of inappropriate uses that deal with the overuse and 
surface logicality. Although the other misuse patterns (non-equivalent exchange, wrong relation, semantic incompletion, and distraction) were found rarely used in EFL student presentations, it is necessary to increase students' awareness on the misuse patterns to optimize their understanding on employing various DMs.

\section{Conclusions}

This research found out that all types of DMs are used by students. The most frequently used type of DMs is elaborative markers that are in accordance with the topic of the student presentation that is related to descriptions. The five frequently used variants found in student presentation are and, also, but, so, and however.

Students are able to use DMs in their presentation in the beginning, in the middle, and in the end of presentation by looking at the relevance of the DM functions and the context it is embedded. However, the misuses were found that include overuse, surface logicality, nonequivalent exchange, wrong relation, semantic incompletion, and distraction. The students have a tendency to misuse DMs categorized as overuse and surface logicality.

From the findings and discussion, the researchers provide suggestions for future researchers who have similar interests to investigate DMs in spoken discourse. The study on the use of DMs in student presentations should be investigated more by focusing on the opening, the body, and the closing. The movement from one to another section may use topic change markers that could add insightful results. The next interesting topic is pertinent to the students' strategy in order to build coherence and cohesion in a discourse. The strategy can inspire other learners and raise their awareness on building unity of ideas in a discourse.

\section{Acknowledgements}

The researchers would like to thank the editors and reviewers for the suggestions on the manuscript. This research was supported by DIPA research grant number 023.18.2.677632/2020, State Polytechnic of Madiun.

\section{References}

[1] T. Rahayu and B. Y. Cahyono, "Discourse Markers in Expository Essays Written by Indonesian Students of EFL,” Int. J. Lang. Linguist., vol. 2, no. 2, pp. 21-29, 2015.

[2] M. Md Yunus and S. N. F. Haris, "The use of discourse markers among form four SLL students in essay writing," Int. Educ. Stud., vol. 7, no. 2, pp. 54-63, 2014, doi: 10.5539/ies.v7n2p54.

[3] J. E. Fox Tree, "Discourse Markers in Writing. Discourse Studies," Discourse Stud., vol. 17, no. 1, pp. 64-82, 2015.

[4] A. Aşik and P. T. Cephe, "Discourse markers and spoken English: Nonnative use in the Turkish EFL setting," English Lang. Teach., vol. 6, no. 12, pp. 144-155, 2013, doi: 10.5539/elt.v6n12p144.

[5] S. Ali Saad Al-Yaari, F. Saleh Al Hammadi, S. Ayied Alyami, and N. Almaflehi, "Using English Discourse Markers (EDMs) by Saudi EFL Learners: A Descriptive Approach," Int. J. English Lang. Educ., vol. 1, no. 2, pp. 1-26, 2013, doi: 10.5296/ijele.v1i2.3058. 
[6] R. Banguis-Bantawig, "The role of discourse markers in the speeches of selected Asian Presidents," Heliyon, vol. 5, no. 3, p. e01298, 2019, doi: 10.1016/j.heliyon.2019.e01298.

[7] L. Crible and M.-J. Cuenca, "Discourse Markers in Speech: Distinctive Features and Corpus Annotation," Dialogue \& Discourse, vol. 8, no. 2, pp. 149-166, 2017, doi: 10.5087/dad.2017.207.

[8] J. R. Garner, "The Use of Linking Adverbials in Academic Essay by Non-native Writers: How Data-Driven Learning Can Help," Calico J., vol. 30, no. 3, pp. 410-422, 2013.

[9] Y. L. Lin, "Discourse marking in spoken intercultural communication between British and Taiwanese adolescent learners," Pragmatics, vol. 26, no. 2, pp. 221-245, 2016, doi: 10.1075/prag.26.2.03lin.

[10] D. Rongrong and W. Lixun, "Discourse Markers in Local and Native English Teachers' Talk in Hong Kong EFL Classroom Interaction: A Corpus-Based Study," Int. J. Lang. Linguist., vol. 2, no. 5, pp. 65-75, 2015.

[11] G. Vickov and E. Jakupčević, "Discourse markers in non-native EFL teacher talk," Stud. Second Lang. Learn. Teach., vol. 7, no. 4, pp. 649-671, 2017, doi: 10.14746/ssllt.2017.7.4.5.

[12] B. Fraser, "Topic Orientation Markers," J. Pragmat., vol. 41, no. 5, pp. 892-898, 2009, doi: 10.1016/j.pragma.2008.08.006.

[13] J. Harmer, How to teach English, vol. null. Essex: Pearson Education Limited, 2010.

[14] B. Fraser, "What are Discourse Markers," J. Pragmat., vol. 31, pp. 931-952, 1999.

[15] M. Parrot, Grammar for English Language Teachers, Second., no. 2. Cambridge: Cambridge University Press, 2012.

[16] T.-Y. Kao and L. Chen, "Diagnosing discoursal organization in learner writing via conjunctive adverbials," Proc. 23rd \{Conference\} \{Computational\} \{Linguistics\} \{Speech\} \{Processing\} (\{ROCLING\} 2011), pp. 310-322, 2011, [Online]. Available: http://www.aclweb.org/anthology/O11-2010. 